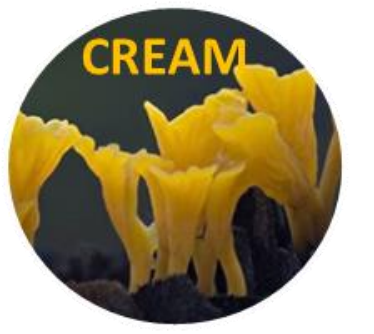

Current Research in Environmental \& Applied Mycology 6 (3): 202-209(2016) ISSN 2229-2225

www.creamjournal.org

Article

CREAM

Copyright @ 2016

Doi 10.5943/cream/6/3/8

Online Edition

\title{
In Vitro antimicrobial potentials of four Ramalina lichen species from Turkey
}

\author{
Sesal $C^{1}$, Çobanoğlu $\mathbf{G}^{1}$, Karaltı $\dot{I}^{2}$ and Açıkgöz B ${ }^{1}$ \\ ${ }^{1}$ Marmara University, Science and Art Faculty, Department of Biology, Goztepe Campus, Istanbul, Turkey \\ ${ }^{2}$ Yeditepe University, Faculty of Health Sciences, Department of Nutrition and Dietetics, Istanbul, Turkey
}

Sesal C, Çobanoğlu G, Karaltı İ, Açıkgöz B 2016 - In vitro antimicrobial potentials of four Ramalina lichen species from Turkey. Current Research in Environmental \& Applied Mycology6(3), 202-209, Doi $10.5943 /$ cream/6/3/8

\begin{abstract}
The present study, aiming to explore pharmaceutical potential, appraises the antimicrobial effects of four epiphytic fruticose lichen species, Ramalina canariensis J.Steiner, Ramalina chondrina J.Steiner, Ramalina fastigiata (Pers.) Ach., and Ramalina fraxinea (L.) Ach. In vitro antimicrobial activities of methanol and chloroform extracts against two Gram-negative bacteria (Pseudomonas aeruginosa ATCC 15442 and Escherichia coli ATCC 2592), two Gram-positive bacteria (Enterococcus faecalis ATCC 29212 and Staphylococcus aureus ATCC 25923), and the yeast Candida albicans ATCC 90028 were tested with paper disc method, through determination of minimal inhibitory concentrations (MICs). The results indicated that chloroform and methanol extracts of the examined species demonstrated inhibitory activity against the growth of the tested microorganisms in different levels. That activity was more evident in chloroform extracts of Ramalina canariensis and Ramalina chondrina against $E$. coli than the methanol extracts. The methanol extract of Ramalina canariensis was the most active against $C$. albicans.
\end{abstract}

Key words - antimicrobial activity - antifungal effect

\section{Introduction}

Lichens, in other words "lichenized fungi", are known as symbiotic associations between fungi and algae, including more than 20,000 species on the earth, inhabiting over the terrestrial habitats from arctic to tropical regions. These unique organisms are able to produce secondary metabolites, usually aromatic and acidic substances, specific to lichens. Lichen substances, which have been reported to date more than 1000 (Molnar \& Farkas 2010), are mostly small but complex molecules, having a big pharmaceutical potential.

Besides the knowledge based on historic medicinal uses for centuries (Cobanoğlu \& Yavuz 2003, Yavuz \& Cobanoğlu 2010, Yavuz 2012), it is known that lichens have also been widely used in pharmaceutical and other industries of such as food, cosmetics and dye. Most of the preliminary information on potential biological activity of lichen metabolites is based upon their ethnic and traditional utilization (Llano 1950, Ingolfsdottir 2002, Romagni \& Dayan 2002).

Nowadays, numerous lichen species showing biological activities with regard to antimicrobial (Ranković et al. 2009, Mitrović et al. 2011), antifungal (Proksa et al. 1996, Halama \& Van Haluwyn 2004, Schmeda-Hirschmann et al. 2008), antioxidative (Aslan et al. 2006, Luo et al. 2009, Ranković et al. 2010), cytotoxic (Karagoz \& Aslan 2005, Açıkgöz et al. 2013) and anticancer (Bačkorová et al. Submitted 21 June 2016, Accepted 22 August 2016, Published online 28 August 2016 
2012, Coskun et al. 2015) etc. have been reported. The grade of these activities depends on the species of lichen as well as its locality, type of the solvent, amount of the extract, and the tested microorganisms.

Due to the increase in difficulty in the treatment of drug-resistant microorganisms and diseases, the necessity of alternative effective antimicrobial drug development has emerged. With respect to this, lichens can be used as natural antimicrobial agents (Shukla et al. 2010), and the lichen metabolites have been thought to be an alternative way of producing new-designed drugs.

Chemistry of lichens in terms of pathways leading to the formation of secondary metabolites continues to be discovered with the developing methodology. A lot of lichen species has been analysed in the recent decades and several compounds, presumably of fungal origin, have been detected. The chemical structures of these lichen-specific metabolites are mostly polyketides, polyphenols, quinones or terpenoids (Eisenreich et al. 2011).

Many species of the genus Ramalina that have been traditionally used in folk medicine, were reported to possess bioactive molecules (Ingolfsdottir 2002, Romagni \& Dayan 2002, Moreira et al. 2015). Antimicrobial activities of crude extracts of some Ramalina species were presented in previous papers (Tay et al. 2004, Cobanoglu et al. 2010, Santiago et al. 2010, Ristić et al. 2016). Antioxidant constituents were found in $R$. terebrata (Bhattarai et al. 2008). Antibacterial, antifungal, and cytotoxic properties of $R$. farinacea were evaluated by Esimone and Adikwu (1999). $R$. farinacea was also evaluated in terms of its in vitro antiviral activity (Esimone et al. 2009, Lai et al. 2013). Antimicrobial and antioxidant activities of $R$. farinacea, $R$. fastigiata and $R$. fraxinea were examined recently by Şahin et al. (2015). Some studies related to antimicrobial activity of Ramalina deal with the chemical constituents of the species more significantly (Tay et al. 2004, Saenz et al. 2006, Cansaran et al. 2007, Hanuš et al. 2008, Paudel et al. 2010, Ristić et al. 2016).

The present study evaluates the antimicrobial potentials of the extracts of four Ramalina species, Ramalina canariensis J.Steiner, Ramalina chondrina J.Steiner, Ramalina fastigiata (Pers.) Ach. and Ramalina fraxinea (L.) Ach. quite common in Turkey. It is intended to contribute to the uses of lichens in pharmacological purposes.

\section{Materials \& Methods}

\section{Lichen Material}

Lichen material collected from Kocaeli and Bolu provinces in the northwest of Turkey were identified through classical taxonomic methods (Smith et al. 2009, Wirth 1995) with microscopic investigations (Stereomicroscope, Olympus SZ40; Olympus Medical Systems Corp., Tokyo, Japan). The nomenclature follows the index fungorum (www.indexfungorum.org 2016). The studied four fruticose lichen species with remarks about their collecting information (locality, coordinates, substrate, date and altitude) are the following:

Ramalina canariensis J.Steiner: Turkey, Kocaeli province, Kandıra Town, Sarısu area, $41^{\circ} 08^{\prime 23.4 \prime}$ N -

03009'34.4" E, on Quercus infectoria Olivier, bark, 23.4.2010, 13 m, G.Çobanoğlu.

Ramalina chondrina J.Steiner: Turkey, Bolu province, Şerif Yüksel Research Forest, $40^{\circ} 37^{\prime} 41^{\prime \prime} \mathrm{N}-25^{\circ}$

34' 23" E, on Abies bornmuelleriana Mattf., bark, 4.4.2010, 1590 m, G.Çobanoğlu.

Ramalina fastigiata (Pers.) Ach.: Turkey, Bolu province, Şerif Yüksel Research Forest, 40'37'41" N 25 34' 23" E, on Abies bornmuelleriana Mattf., bark, 4.4.2010, 1590 m, G.Çobanoğlu.

Ramalina fraxinea (L.) Ach.: Turkey, Bolu province, Şerif Yüksel Research Forest, 40 37'41" N - $25^{\circ}$ 34' 23" E, on Abies bornmuelleriana Mattf., bark, 4.4.2010, 1590 m, G.Çobanoğlu.

\section{Test Microorganisms}

The test microorganisms, Pseudomonas aeruginosa ATCC 15442, Escherichia coli ATCC 2592, Enterococcus faecalis ATCC 29212, Staphylococcus aureus ATCC 25923, and Candida albicans ATCC 90028, were provided by the Medical Microbiology Department of the Medicine Faculty of Yeditepe University, Istanbul, Turkey. 


\section{Preparation of Lichen Extracts}

The air-dried samples were ground by means of a mortar and a pestle. Powdered lichen materials $(5 \mathrm{~g})$ from the samples of $R$. canariensis, $R$. chondrina, $R$. fastigiata and $R$. fraxinea, were successively extracted in a Soxhlet extractor apparatus using $250 \mathrm{ml}$ of methanol and chloroform as solvents, respectively. The extracts were filtered through Whatman No. 1 filter paper (Whatman, Maidstone, England) and the solvents then evaporated by a rotary evaporator to dryness under reduced pressure to yield crude extracts of $77 \mathrm{mg}$ for $R$. canariensis $114 \mathrm{mg} R$. chondrina, $250 \mathrm{mg} R$. fastigiata, and $260 \mathrm{mg} R$. fraxinea from the methanol. From the chloroform, the yields of crude extracts were 4, 6 , 130 and $110 \mathrm{mg}$, respectively. The extracts were dissolved in the solvents, methanol and chloroform and sterilized by membrane filtration using $0.45-\mu \mathrm{m}$ pore-sized Millipore filters (MF-Millipore, Billerica, MA, USA), and were kept at $-20{ }^{\circ} \mathrm{C}$ until assay.

\section{Antimicrobial Assays}

The disc diffusion susceptibility test was used for the test microorganisms which were grown in nutrient broth (NB-No. 3, for microbiology, 70149 Fluka, Munich, Germany) in incubators at $37{ }^{\circ} \mathrm{C}$, overnight for bacterial strains and $48 \mathrm{~h}$ for the yeast strain. They were diluted to $0.5 \mathrm{Mc}$ Farland standards approximately $10^{8} \mathrm{cfu} / \mathrm{ml}$ for bacteria and $10^{6} \mathrm{cfu} / \mathrm{ml}$ for C. albicans. Then the bacteria and C. albicans were spread on nutrient agar plates (Salubris, Istanbul, Turkey) and Muller Hinton Agar (MHA) (Sigma-Aldrich, Munich, Germany), respectively. For the disc diffusion assay, the dried extracts were dissolved in the solvents, methanol and chloroform; diluted 1:10 and then sterilized by filtration through $0.45 \mu \mathrm{m}$ Millipore filters, respectively. Each of the final concentrations of $20 \mu \mathrm{l}$ doses of the methanol and the chloroform solutions were added onto Whatman filter paper discs $(6 \mathrm{~mm}$ diameter) allowing the solvent to evaporate during the applications (Bauer et al. 1966). After detecting a non-antimicrobial dose of methanol and chloroform they were applied for the antimicrobial tests.

Negative controls were prepared by using the respective solvents employed to dissolve the lichen extracts. A number of antibiotics were used as positive reference standards for the bacteria; Ciprofloxacin $(5 \mu \mathrm{g} / \mathrm{disc})$, Chloramphenicol $(30 \mu \mathrm{g} / \mathrm{disc})$ and Vancomycin $(30 \mu \mathrm{g} / \mathrm{disc})$, and for the yeast; Fluconazole $(25 \mu \mathrm{g} /$ disc). Since all microbiological tests were made in laboratories with an International Quality Certification (ISO-15189), a large antibiotic control panel recommended by CLSI (Clinical Laboratory Standards Institute, formerly NCCLS) was used. CLSI has proposed a reference broth macrodilution method for in vitro antifungal susceptibility testing of yeasts (the M27-P method). This method includes MIC endpoint determination by the visual and subjective observation of growth inhibition after $48 \mathrm{~h}$ of incubation.

The bacterial inhibition zones on the test plates were measured under the bacterial colony counter Colony Star (Funke-Gerber, Berlin, Germany). The final concentrations of each solution, which exhibited relatively larger zones of inhibition, were diluted serially from one to ten-fold to determine the minimal inhibitory concentrations (MIC). The serial dilutions were tested on the microorganisms during overnight incubation. All experiments were done in triplicate and checked with the control plates.

\section{Statistical Analysis}

All values were expressed as mean \pm SD calculated by Descriptive statistics. SPSS 20 statistics package was used for the analysis.

\section{Results}

This study was designed to evaluate qualitative antimicrobial potentials of four Ramalina species, $R$. canariensis, $R$. chondrina, $R$. fastigiata and $R$. fraxinea, against the microorganisms, $P$. aeruginosa, E. faecalis, $S$. aureus, E. coli and C. albicans. The inhibitory effects of chloroform and methanol extracts of the species were tested through disc diffusion assay, and the diameters of growth inhibition zones were indicated in the Table 1. The determined values of the minimal inhibitory concentration (MIC) were shown in the Table 2. 
It is clearly remarked that the chloroform as a solvent was more effective against Gramnegative bacteria than the methanol according to our experimental results. The chloroform extracts of $R$. canariensis and $R$. chondrina were found to have particularly higher antibacterial activity against $E$. coli and $P$. aeruginosa. While none of the extracts of $R$. fastigiata and $R$. fraxinea had inhibitory effect on the same bacteria.

The chloroform extract of $R$. canariensis indicated the highest activity on $P$. aeruginosa and $E$. coli with inhibition zones of 32 and $31 \mathrm{~mm}$, respectively, better than that of the antibiotic's (CIP) with 29 and $24 \mathrm{~mm}$. The lowest activity of the chloroform extract was against E. faecalis. However, when compared to the doses used, the chloroform extract containing a lower dose $(8 \mu \mathrm{g} / \mathrm{disc})$ observed in this case is more effective than antibiotics (30 $\mathrm{g}$ /disc) (Table 1). The methanol extracts of $R$. canariensis had no antibacterial effect against to E. coli, P. aeruginosa and E. faecalis. Otherwise, the both extracts of $R$. canariensis were found to have similar antibacterial activity on $S$. aureus at quite high levels. But, again, compared to doses contained in the disc, it appears that particularly the chloroform extract has quite high antibacterial effect than the antibiotics against $S$. aureus. Moreover, the both of chloroform and methanol extracts of $R$. canariensis had antifungal effects against the yeast $C$. albicans, particularly the methanol extract showed the highest activity with the inhibition zone of $31 \mathrm{~mm}$ higher than Fluconazole with $25 \mathrm{~mm}$.

The chloroform extract of $R$. chondrina had the strongest antimicrobial activity against $E$. coli tested with growth inhibition zone diameter of $32 \mathrm{~mm}$ ranged over the antibiotic CIP with $24 \mathrm{~mm}$. The both methanol and chloroform extracts of this species exhibited a moderate antibacterial activity against $S$. aureus. Also, the methanol extract of $R$. chondrina had a weak effect on $C$. albicans although its chloroform extract did not exhibit any antifungal activity.

The inhibition effects of $R$. fraxinea with both chloroform and methanol extracts were higher than the antibiotic (VAN) against $E$. faecalis. All the lichen extracts were moderately active against $S$. aureus. Inhibitory effect of $R$. fastigiata was very low compared to the other lichen species. However, the extracts of both $R$. fraxinea and $R$. fastigiata showed no antifungal activity.

In a negative control, the chloroform and the methanol in applied concentrations of the lichen extracts as solvents had no inhibitory effect on the tested organisms.

\section{Discussion}

Several current studies with biological activities of Ramalina are available. The main differences between activity powers are based on solvent types. Cobanoglu et al. (2010) reported five lichen species including $R$. farinacea, that both of the acetone and the chloroform extracts exhibited antimicrobial activity against $E$. coli and $P$. aeruginosa. In the present study, the chloroform extracts of two of the tested Ramalina species, $R$. canariensis and $R$. chondrina, exhibited a highly significant effect on these two Gram negative bacteria. In addition, the acetone as a solvent was notified more effective compared to the chloroform by Cobanoglu et al. (2010). Also, acetone extraction of Ramalina menziesii compared to the methanol extract was reported that showed greater activity against $S$. aureus and $P$. aeruginosa but not against $E$. coli (Shrestha \& St. Clair 2013). The antimicrobial disc diffusion assay of crude extracts from $R$. dendriscoides dissolved in acetone showed high activity against $S$. aureus and B. subtilis (Santiago et al. 2010). The water, ethanol, chloroform and n-hexane extracts of the lichen $R$. farinacea have been evaluated for their phytochemical constituents, antibacterial, antifungal, and cytotoxic properties by Esimone \& Adikwu (1999). Eventually, ethanol and n-hexane extracts showed the highest antimicrobial activity on $S$. aureus, $P$. aeruginosa, E. coli and C. albicans. Their results show similarity with the activity of chloroform extract of $R$. canariensis against the same organisms in this study.

Mitrović et al. (2011) underlined in vitro testing of the antibacterial activities of the methanol extracts of Hypogymnia physodes and Cladonia foliacea with more potent inhibitory effects on the growth of Gram positive bacteria. Similarly in this study, methanol extracts of $R$. fraxinea exhibited very high antibacterial effect on E. faecalis. Moreover if compared to doses contained in the disc, methanol extracts of $R$. fraxinea and $R$. fastigiata showed more strong inhibitory effects also against $S$. 
aureus than the control (Table 1). Overall methanol extracts, which had no effect against Gram negative bacteria showed very high activity against Gram positives.

Table 1 Antimicrobial activities of the lichen extracts based on disc-diffusion assay.

\begin{tabular}{lllllll}
\hline & & E. coli & P. aeruginosa & E. faecalis & S. aureus & C. albicans \\
\hline R. canariensis & M & - & - & - & $19 \pm 0.57$ & $31 \pm 0.58$ \\
& C & $31 \pm 0.58$ & $32 \pm 0.00$ & $7 \pm 1.00$ & $18 \pm 0.58$ & $17 \pm 1.15$ \\
R. chondrina & M & - & - & - & $10 \pm 1.52$ & $10 \pm 0.58$ \\
& C & $32 \pm 1.15$ & $15 \pm 1.00$ & $7 \pm 0.58$ & $10 \pm 1.00$ & - \\
R. fastigiata & M & - & - & $11 \pm 1.00$ & $11 \pm 0.58$ & - \\
& C & - & - & $12 \pm 1.00$ & $10 \pm 2$ & - \\
R. fraxinea & M & - & - & $17 \pm 0.58$ & $9 \pm 0.58$ & - \\
& C & - & - & $15 \pm 1.15$ & $9 \pm 0.58$ & - \\
& CIP & $24 \pm 0.00$ & $29 \pm 0.00$ & & & \\
& CHL & & & & $22 \pm 0.58$ & \\
& VAN & & & $14 \pm 0.57$ & & $25 \pm 0.58$ \\
\hline
\end{tabular}

Values are mean inhibition zone diameters \pm SD (in $\mathrm{mm}$ ) of three replicates, - no inhibition observed

C: Chloroform extract, $\mathbf{M}$ : Methanol extract

*Antibiotics used as positive reference standards to determine the sensitivity of microorganisms;

CIP: Ciprofloxacin, CHL: Chloramphenicol, VAN: Vancomycin, FLU: Fluconazole

Table 2 Minimum inhibitory concentration (MIC) values of the lichen extracts in $\mu \mathrm{g} / \mathrm{ml}$.

\begin{tabular}{|c|c|c|c|c|c|c|}
\hline & & E. coli & P. aeruginosa & E. faecalis & S. aureus & C. albicans \\
\hline \multirow[t]{2}{*}{ R. canariensis } & $\mathrm{M}$ & - & - & - & $77 \pm 1.00$ & $15.4 \pm 0.00$ \\
\hline & $\mathrm{C}$ & $1.6 \pm 0.58$ & $1.6 \pm 0.58$ & $5.6 \pm 0.58$ & $3.2 \pm 0.58$ & $4 \pm 0.58$ \\
\hline \multirow[t]{2}{*}{ R. chondrina } & M & - & - & - & - & - \\
\hline & $\mathrm{C}$ & $1.2 \pm 0.58$ & $4.8 \pm 0.58$ & - & - & - \\
\hline \multirow[t]{2}{*}{ R. fastigiata } & M & - & - & $133 \pm 0.58$ & $33 \pm 0.00$ & - \\
\hline & $\mathrm{C}$ & - & - & $69 \pm 0.58$ & $35 \pm 0.58$ & - \\
\hline \multirow[t]{2}{*}{$R$. fraxinea } & M & - & - & $138 \pm 1.00$ & - & - \\
\hline & $\mathrm{C}$ & - & - & $59 \pm 1.00$ & - & - \\
\hline
\end{tabular}

*The MIC values were not determined for the extracts with inhibition zone diameters lower than $10 \mathrm{~mm}$.

Data for the activities of the crude lichen extracts have been presented in a big part of the papers in the literature. In various publications, chemical composition of many lichen species have been also explored to determine substances ensuring the biological activity potential of the lichen extracts. Chemistry and biological activity of Ramalina has been reviewed recently by Moreira et al. (2015). The vast majority of studies in literature were with crude extracts, and about only $18 \%$ of the identified compounds have been tested for biological activities. Usnic acid was the most biologically effective compound with the best results, while the other compounds showing also good results.

In species of Ramalina, usnic acid content is more evident as a bioactive compound compared the other secondary lichen substances (Romagni \& Dayan 2002, Santiago et al. 2010, Shukla et al. 2010). The usnic acid amounts of $R$. fastigiata, $R$. capitata, $R$. polymorpha, $R$. pollinaria and $R$. fraxinea were determined by HPLC analysis and their acetone extracts were tested antimicrobially by Cansaran et al. (2007); resulting that as the usnic acid amount increased, the antimicrobial activities were increased. Saenz et al. (2006) notified the lichen compounds identified from acetone extract of $R$. canariensis as atranorin, lichesterinic acid, stistic acid and usnic acid. These substances had shown high antimicrobial activity in the disc diffusion method against Gram positive bacteria, except atranorin which was the least active compound. A total of five compounds, usnic acid, usimine A, usimine B, usimine $\mathrm{C}$, and ramalin, were isolated from the methanol extract of $R$. terebrata, and all the samples exhibited antibacterial activity against $S$. aureus (Paudel et al. 2010). In addition, usnic acid, constituent of many lichens, was often reported as inactive against Gram negative bacteria $E$. coli and $P$. aeruginosa (Ingolfsdottir et al. 2002, Tay et al. 2004). In a study evaluating the chemical composition 
of water-ethanol extract of the epiphytic species $R$. lacera possessing antibacterial and antifungal activities, Hanuš et al. (2008) stated that orsellinic and diffractaic acids were more active against Gram negative bacteria (E. coli, $P$. aeruginosa) and yeast $C$. albicans compared to usnic acid. $R$. canariensis used in our study is often confused with $R$. lacera since it has very similar morphology. Therefore, in the present study, antimicrobial activity against Gram negative bacteria was probably not due to usnic acid but other constituents of Ramalina species. The results of the present study coincide with the results of a recent research (Ristić et al. 2016), where evernic acid, obtusatic acid, sekikaic acid, atranorin, protocetraric acid and usnic acid were identified from $R$. fraxinea and $R$. fastigiata. Among their constituents, methyl evernate and obtusatic acid showed the strongest antimicrobial capacity. Acetone extract of $R$. fastigiata showed antibacterial activity against $E$. coli but $R$. fraxinea exhibited no inhibition of growth against $E$. coli.

All these studies reveal the promising potential of Ramalina lichen species for the discovery of new antibiotics. The outcomes in this study corroborate the presence of antibiotic substances in the tested lichen extracts. The results about the chloroform extracts of Ramalina chondrina and $R$. canariensis that showed powerful antimicrobial activity against E. coli and P. aeruginosa contributed new data for the literature.

In addition, it is determined that chloroform as a solvent was significantly more effective than methanol on the bacteria, but methanol was more active on the fungus $C$. albicans. The presented evidences about the antimicrobial potentials of lichen extracts may coincide or differ from results of the other studies depending on different sensitivity of tested microorganisms and also on the species of lichen and locations of sampling. The dissimilarities even resulting sometimes from the analysis of the same species must probably occur due to any of the steps in the analysing methods. In order to figure out the effectiveness of each particular substance in lichen samples, the chemical constituents should be investigated in detail and applied for antimicrobial tests in the further studies.

\section{Acknowledgements}

This study is a part of research project supported by The Research Fund of Marmara University with the project number FEN-A-200611-0208.

\section{References}

Açikgöz B, Karalti İ, Ersöz M, Coşkun MZ, Çobanoğlu G, Sesal C. 2013 - Screening of antimicrobial and cytotoxic effects of two Cladonia species. Zeitschrift für Naturforschung C 68c, 191-197.

Aslan A, Gulluce M, Sokmen M, Adiguzel A, Sahin F, Ozkan H. 2006 - Antioxidant and antimicrobial properties of the lichens Cladonia foliacea, Dermatocarpon miniatum, Evernia divaricata, Evernia prunastri and Neofuscelia pulla. Pharmaceutical Biology 44(4), 247-252.

Bačkorová M, Jendželovský R, Kello M, Bačkor M, Mikeš J, Fedoročko P. 2012 - Lichen secondary metabolites are responsible for induction of apoptosis in HT-29 and A2780 human cancer cell lines. Toxicology in Vitro 26, 462-468.

Bauer AW, Kirby WM, Sherris JC, Turck M. 1966 - Antibiotic susceptibility testing by a standardized single disc method. American Journal of Clinical Pathology 45, 493-496.

Bhattarai HD, Paudel B, Hong SG, Lee HK, Yim JH. 2008 - Thin layer chromatography analysis of antioxidant constituents of lichens from Antarctica. Journal of Natural Medicines 62, 481-484.

Cansaran D, Atakol O, Halici MG, Aksoy A. 2007 - HPLC analysis of the usnic acid in some Ramalina species from middle Anatolia and investigation of their antimicrobial activities. Pharmaceutical Biology 45(1), 77-81.

Cobanoglu G, Sesal C, Gokmen B, Çakar S. 2010 - Evaluation of the antimicrobial properties of some lichens. South Western Journal of Horticulture, Biology and Environment 1(2), 153-158.

Cobanoglu G, Yavuz M. 2003 - Tıp tarihinde likenlerle tedavi. Yeni Tıp Tarihi Araştırmaları. The New History of Medicine Studies 9, 37-90. 
Coskun ZM, Ersoz M, Acikgoz B, Karalti I, Cobanoglu G, Sesal C. 2015 - Anti-proliferative and apoptotic effects of methanolic extracts from different Cladonia species on human breast cancer cells. Folia Biologica (Praha) 61, 97-103.

Eisenreich W, Knispel N, Beck A. 2011 - Advanced methods for the study of the chemistry and the metabolism of lichens. Phytochemistry Reviews 10, 445-456.

Esimone CO, Adikwu MU. 1999 - Antimicrobial activity and cytotoxicity of Ramalina farinacea. Fitoterapia 70, 428-431.

Esimone CO, Grunwald T, Nworu CS, Kuate S, Proksch P, Überla K. 2009 - Broad spectrum antiviral fractions from the lichen Ramalina farinacea (L.) Ach. Chemotherapy 55, 119-126. DOI: $10.1159 / 000194974$

Halama P, Van Haluwyn C. 2004 - Antifungal activity of lichen extracts and lichenic acids. Bio Control 49, 95-107.

Hanuš LO, Temina M, Dembitsky VM. 2008 - Antibacterial and antifungal activities of some phenolic metabolites isolated from lichenized ascomycete Ramalina lacera. Natural Product Communications 3, 233-236.

Ingolfsdottir K. 2002 - Molecules of interest -Usnic acid. Phytochemistry. 61, 729-736.

Karagoz A, Aslan A. 2005 - Antiviral and cytotoxic activity of some lichen extracts. Biologia Bratislava 60(3), 281-286.

Lai D, Odimegwu DC, Esimone C, Grunwald T, Proksch P. 2013 - Phenolic compounds with in vitro activity against respiratory syncytial virus from the Nigerian lichen Ramalina farinacea. Planta Medica 79, 1440-1446.

Llano GA. 1950 - Economic uses of lichens. Annual Report, Smithsonian Institution, Washington D.C.

Luo H, Yamamoto Y, Kim JA, Jung JS, Koh YJ, Hur S. 2009 - Lecanoric acid, a secondary lichen substance with antioxidant properties from Umbilicaria antarctica in maritime Antarctica (King George Island). Polar Biology 32, 1033-1040. DOI: 10.1007/s00300-009-0602-9

Mitrović T, Stamenković S, Cvetković V, Tošić S, Stanković M, Radojević I, Stefanović O, Čomić L, Đačić D, Ćurčić M, Marković S. 2011 - Antioxidant, antimicrobial and antiproliferative activities of five lichen species. International Journal of Molecular Sciences 12, 5428-5448. DOI: $10.3390 / \mathrm{ijms} 12085428$

Molnar K, Farkas E. 2010 - Current results on biological activities of lichen secondary metabolites: a review. Zeitschrift für Naturforschung C 65c, 157-173.

Moreira ASN, Braz-Filho R, Mussi-Dias V, Vieira IJC. 2015 - Chemistry and biological activity of Ramalina lichenized fungi. Molecules, 20, 8952- 8987; DOI: 10.3390/molecules20058952

Paudel B, Bhattarai HD, Lee HK, Oh H, Shin HW, Yim JH. 2010 - Antibacterial Activities of Ramalin, Usnic Acid and its Three Derivatives Isolated from the Antarctic Lichen Ramalina terebrata. Zeitschrift für Naturforschung C 65c, 34-38.

Proksa B, Sturdikova M, Na Pronayova Liptaj T. 1996 - Usnic acid and its derivatives: Their inhibition of fungal growth and enzyme activity. Pharmazie 51, 195-196.

Ranković B, Mišic M, Sukdolak S. 2009 - Antimicrobial activity of extracts of the lichens Cladonia furcata, Parmelia caperata, Parmelia pertusa, Hypogymnia physodes and Umbilicaria polyphylla. Biologia 64(1), 53-58. DOI: 10.2478/s11756-009-0007-9

Ranković B, Ranković D, Kosanić M, Maric D. 2010 - Antioxidant and antimicrobial properties of the lichens Anaptychya ciliaris, Nephroma parile, Ochrolechia tartarea and Parmelia centrifuga. Central European Journal of Biology 5, 649-655. DOI: 10.2478/s11535-010-0043-z

Ristić S, Rankovic B, Kosanić M, Stamenkovic S, Stanojković T, Sovrlić M, Manojlović N. 2016 Biopharmaceutical Potential of Two Ramalina Lichens and their Metabolites. Current Pharmaceutical Biotechnology 17, 651-658.

Romagni JG, Dayan FE. 2002 - Structural diversity of lichen metabolites and their potential use, in: Upadhyay, R.K. (Ed.), Advances in microbial toxin research and its biotechnological exploitation. Kluwer Academic / Plenum Publ., pp. 151-170.

Saenz MT, Garcia MD, Rowe JG. 2006 - Antimicrobial activity and phytochemical studies of some lichens from south of Spain. Fitoterapia 77, 156-159. 
Şahin S, Oran S, Şahintürk P, Demir C, Öztürk Ş. 2015 - Ramalina lichens and their major metabolites as possible natural antioxidant and antimicrobial agents. Journal of Food Biochemistry 39, 471477. DOI: $10.1111 /$ jfbc. 12142

Santiago KKA, Borricano JNC, Canal JN, Marcelo DMA, Perez MCP, Dela Cruz TEE. 2010 Antibacterial activities of fruticose lichens collected from selected sites in Luzon Island, Philippines. Philippine Science Letters 3, 18-29.

Schmeda-Hirschmann G, Tapia A, Lima B, Pertino M, Sortino M, Zacchino S, Arias AR, Feresin GE. 2008 - A new antifungal and antiprotozoal depside from the Andean lichen Protousnea poeppigii. Phytotherapy Research 22, 349-355.

Shrestha G, St. Clair LL. 2013- Antimicrobial Activity of Extracts from Two Lichens Ramalina menziesii and Usnea lapponica. Bulletin of The California Lichen Society 20, 5-10.

Shukla V, Joshi GP, Rawat MSM. 2010 - Lichens as a potential natural source of bioactive compounds: a review. Phytochemistry Reviews 9, 303-314.

Smith CW, Aptroot A, Coppins BJ, Fletcher A, Gilbert OL, James PW, Wolseley PA. 2009 - The lichens of Great Britain and Ireland. The British Lichen Society, London.

Tay T, Turk Özdemir A, Yilmaz M, Turk H, Kivanc M. 2004 - Evaluation of the antimicrobial activity of the acetone extract of the lichen Ramalina farinacea and its (+)-usnic acid, norstictic acid, and protocetraric acid constituents. Zeitschrift für Naturforschung C 59c, 384-388.

Wirth V. 1995 - Die flechten. Baden-Württembergs. Teil 1-2. Eugen Ulmer. Stuttgart.

www.indexfungorum.org - 2016.

Yavuz M, Cobanoglu G. 2010 - Ethnological uses and etymology of the word Usnea in Ebubekir Razi's "Liber Almansoris". The British Lichen Society Bulletin 106, 3-12.

Yavuz M. 2012 - Lichens mentioned by Pedanios Dioscorides. Studies on Ethno-Medicine 6, 103-109. 